\title{
Preoperative Modic changes are related to axial symptoms after anterior cervical discectomy and fusion
}

Jiaming Zhou'

Liandong $\mathrm{Li}^{\prime}$

Tengshuai $\mathrm{Li}^{2}$

Yuan Xue'

'Department of Orthopedics Surgery, Tianjin Medical University General Hospital, Heping District, Tianjin 300052, People's Republic of China; ${ }^{2}$ Department of Orthopedics Surgery, Tianjin Hospital, Hexi District, Tianjin 3002 II, People's Republic of China

Correspondence: Yuan Xue Department of Orthopedics Surgery, Tianjin Medical University General Hospital, No. 154 Anshan Road, Heping District, Tianjin 300052, People's Republic of China

$\mathrm{Tel}+862260814688$

Fax +86 22 2721 9052

Email xueyuanzyy@।63.com
This article was published in the following Dove Press journal: Journal of Pain Research

Background: The objective of this study was to compare the clinical and radiological outcomes between patients with or without axial symptoms (AS) and investigate the risk factors associated with AS by multivariate regression analysis in anterior cervical discectomy and fusion (ACDF). Materials and methods: The records of 117 patients who underwent ACDF were reviewed for clinical and radiological outcomes. These outcomes were evaluated before and after surgery and at the last follow-up. Preoperative Modic changes (MCs) adjacent to the treated disc were identified. Risk factors for AS were detected through logistic regression analysis.

Results: The patients were divided into two groups: one with AS (AS group, $n=35$ ) and the other without (NAS group, $\mathrm{n}=82)$. Visual Analog Scale values after the operation $(P=0.013)$ and at final follow-up $(P<0.001)$ and preoperative segmental angle $(P=0.031)$ were significantly different between the two groups. There were no significant differences with respect to other clinical and radiographic outcomes between the two groups $(P>0.05)$. Logistic regression analysis revealed that preoperative segmental kyphosis $(\mathrm{OR}=2.912, P=0.035)$ and $\mathrm{MCs}$ (odds ratio $=3.268, P=0.015$ ) were the risk factors for the occurrence of AS.

Conclusion: AS do not correlate with recovery of neural function in patients treated by ACDF. In addition, preoperative segmental kyphosis and $\mathrm{MCs}$ at the fusion segment were found to affect the incidence of AS after ACDF.

Keywords: anterior cervical discectomy and fusion, cervical spondylotic myelopathy, axial symptoms, segmental angle, Modic changes

\section{Introduction}

Cervical spondylotic myelopathy (CSM) is a common cause of nontraumatic quadriplegia and can severely reduce independence and quality of life. ${ }^{1,2}$ First introduced by Smith and Robinson ${ }^{3}$ and Cloward, ${ }^{4}$ anterior cervical discectomy and fusion (ACDF) is considered a standard surgical treatment for affected patients in whom nonoperative treatments fail. ${ }^{5,6}$ ACDF can achieve stabilization and solid arthrodesis with good clinical outcomes and minimal surgical risks.

Axial symptoms (AS) are frequent complaints after cervical spinal surgery including laminoplasty and $\mathrm{ACDF}^{7-9}$ It may cause shoulder and neck pain and movement restrictions after surgery. These symptoms can adversely affect the patient's life, work, and the curative effect of the treatment. ${ }^{10}$

Modic changes (MCs) are vertebral endplate and bone marrow changes visible on magnetic resonance imaging (MRI) that were first identified and classified by Modic. ${ }^{11,12}$ Type I Modic changes (MC1) (hypointense on T1-weighted image [T1WI] and 
hyperintense on T2-weighted image [T2WI]) represent disrupted and fissured endplates and vascular granulation tissue adjacent to the endplates, which corresponding to vertebral body lesions; type II Modic changes (MC2) (hyperintense on both T1WI and T2WI) indicate fatty replacements of the red bone marrow; and type III Modic changes (MC3) (hypointense on both T1WI and T2WI) are thought to represent subchondral bone sclerosis. ${ }^{12-15}$ MCs have been confirmed to be related to low back pain and neck pain in the lumbar spine and cervical spine, respectively. ${ }^{16-18,19}$ Recently, a study illustrated that MCs in the cervical spine could negatively affect $\mathrm{AS}$ intensity after $\mathrm{ACDF}{ }^{20}$

Although several studies have investigated the cause of AS after laminoplasty, few have studied the risk factors of AS following ACDF. Additionally, the incidence, characteristics, and risk factors of AS after ACDF have also not been fully studied. Therefore, the aims of the present study were to compare the clinical and radiological outcomes between patients with or without AS and clarify the correlative risk factors of AS after ACDF.

\section{Materials and methods}

\section{Study population and management}

The present retrospective cohort study included 117 patients (61 male and 56 female) who underwent single-level ACDF between 2012 and 2016 at Tianjin Medical University General Hospital. These patients were observed for a mean duration of 23.28 months (range 12-48 months). The study was approved by the Medical Ethics Committee of our hospital and conducted in accordance with the ethical standards of the Declaration of Helsinki. Written informed consent was obtained from all patients.

The following patients were included: 1) those with cervical MRI-confirmed CSM and corresponding clinical findings and who were unresponsive to appropriate nonsurgical measures for at least 6 months; and 2) those whose operative levels included C3-C4, C4-C5, C5-C6, and C6-C7. The following patients were excluded: those with 1) osteoporosis, trauma, tumor, continuous or combined ossification of the posterior longitudinal ligament; 2) rheumatic or rheumatoid arthritis disease or other serious systemic diseases; 3 ) previous surgery of the cervical spine; 4) multilevel surgery; 5) lack of adequate follow-up (FU) data.

\section{Surgical technique}

All patients received ACDF by the same surgical team. A standard anterolateral approach from the right side was performed to expose the targeted segment. The compressive materials including herniated disc and posterior longitudinal ligament were removed. After cartilage end plate removal, the bony endplates were protected to prevent subsidence. Then, an appropriate-sized cage (Medtronic Sofamor Danek, Memphis, TN, USA) filled with allograft bone was used. Finally, the anterior plate system was applied (Medtronic Sofamor Danek). Postoperatively, all patients were encouraged to resume their normal activities as soon as possible with a cervical collar to avoid overextension for 4 weeks.

\section{Clinical evaluation}

The Japanese Orthopaedic Association (JOA) score was recorded before and after surgery, and at the final FU. A full score was defined as 17 points, 8 for upper and lower motor functions, 6 for sensory functions, and 3 for bladder and rectal functions. The recovery rate of JOA score, which indicates the degree of normalization after surgery, was calculated as $100 \times$ (postoperative score - preoperative score)/[17 (full score) - preoperative score] (\%). Neck pain was evaluated using the Visual Analog Scale (VAS) before and after surgery, and at the final FU. ${ }^{21}$

AS were graded into three levels, as reported by Hosono et al: ${ }^{8}$ mild (no treatment needed), moderate (physical therapy including massage or thermotherapy to alleviate muscular pain regularly needed), and severe (analgesics or injection of anesthetics to the painful muscles regularly needed). Severeor moderate-grade complaints lasting for more than 1 month was considered confirmatory for AS. AS were evaluated routinely at each FU and recorded. At the last FU, patients were divided into two groups according to whether or not they were still experiencing AS.

\section{Imaging assessment}

All of the imaging data were collected and reviewed by two orthopedic surgeons (YX and JZ). Regular meetings and discussions were held to guarantee data reliability. Cervical alignment was obtained by the Cobb method between $\mathrm{C} 2$ and $\mathrm{C} 7$ based on the angle, which was measured by two lines perpendicular to the inferior endplate of the $\mathrm{C} 2$ and the superior endplate of the $\mathrm{C} 7$, respectively. ${ }^{22}$ The segmental angle was defined as the angle formed by the upper plane and the lower plane of the fused segment. The intervertebral height (IH) was defined as the mean value between the anterior and posterior distance of the superior endplate of the cranial vertebral body and inferior endplate of the caudal vertebral body in the surgical segment. IH change was calculated as the difference between IH before and after the surgery. Existing MCs in the endplates adjacent to treated disc were identified through MRI. 


\section{Power calculation}

Based on previous studies and our pilot experiment, we assumed normal distribution and a JOA SD of 2. With a two-sided $\alpha=0.05$, a sample size of 63 patients in each group gave a power of 0.8 to detect a mean difference of 1 in JOA.

\section{Risk factor analysis}

Patients' characteristics including age, sex, smoking status, body mass index (BMI), and the results of their radiological assessment were considered to analyze the risk factors.

\section{Statistical analysis}

All relevant data were collected, and SPSS software version 21.0 (IBM Corporation, Armonk, NY, USA) was used for the statistical evaluation. Variables between the two groups were compared using an independent $t$-test and chi-squared test. The radiological and clinical outcomes prior to surgery, immediately after surgery, and at the last FU were compared using a paired $t$-test and Wilcoxon signed rank test. Multivariate logistic regression analysis was used for correlative risk factor analysis. Significance of parameters was evaluated using univariate analysis. Factors with $P<0.20$ in the univariate analysis were then included in the multivariate analysis. A $P$-value of $<0.05$ was considered statistically significant.

\section{Results}

\section{Patient characteristics}

According to the presence or absence of AS after surgery, the patients were divided into two groups: one with AS (AS group, $n=35$ ) and the other one without (NAS group, $n=82$ ). AS occurred in 35 of 117 (29.91\%) patients. The demographics of the included patients are shown in Table 1. In terms of perioperative parameters, no significant differences were

Table I Patients' characteristics

\begin{tabular}{|l|l|l|l|}
\hline Baseline & AS (n=35) & NAS (n=82) & $P$-value \\
\hline $\begin{array}{l}\text { Age (years) } \\
\text { Gender (n) }\end{array}$ & $57.02 \pm 7.11$ & $55.76 \pm 7.36$ & 0.394 \\
$\quad$ Male & 16 & 45 & \\
Female & 19 & 37 & 0.364 \\
Smoking (n) & & & \\
$\quad$ Smoker & 9 & 17 & \\
Nonsmoker & 26 & 65 & 0.553 \\
BMI (kg/m²) & $24.57 \pm 2.12$ & $24.08 \pm 2.34$ & 0.293 \\
Level (n) & & & \\
C3/4 & 3 & 9 & 0.659 \\
C4/5 & 6 & 20 & \\
C5/6 & 15 & 35 & \\
C6/7 & 11 & 18 & \\
\hline
\end{tabular}

Abbreviation: AS, axial symptoms; BMI, body mass index; NAS, no axial symptoms. observed between the two groups with respect to age, sex, smoking, BMI, and operated level.

\section{Clinical outcomes}

The clinical outcomes of these patients are summarized in Table 2. The JOA scores of both the AS and NAS groups were improved after surgery and at the final FU $(P<0.05)$. In the postoperative period and at the final FU period, the JOA recovery rate was $53.85 \% \pm 14.73 \%$ and $50.37 \% \pm 22.87 \%$, respectively, in the AS group and $56.70 \% \pm 19.95 \%$ and $51.59 \% \pm 21.49 \%$, respectively, in the NAS group. The average JOA score and JOA recovery rate of the two groups showed no significant differences $(P>0.05)$ at any time points. The neck pain in the NAS group was significantly relieved after surgery in terms of the VAS. Although the VAS score increased at the final FU, a significant difference $(P<0.05)$ still existed when compared with preoperative data. In the AS group, VAS related to neck pain was significantly relieved after surgery, while it worsened at the last $\mathrm{FU}(P<0.05$, vs presurgery). Significant differences were found between the two groups after the surgery and the final FU with respect to VAS $(P<0.05)$.

\section{Radiographic results}

The respective cervical alignments in the AS and NAS groups were $5.62 \pm 8.17$ and $7.71 \pm 7.89$ preoperatively, $12.88 \pm 8.24$ and $13.30 \pm 7.28$ postoperatively, and $11.65 \pm 6.84$ and $12.42 \pm 5.85$ at the final FU, respectively. No significant difference $(P>0.05)$ was noted between the two groups at any time point (Table 3 ).

The preoperative segmental angles were $0.94 \pm 8.96$ in the AS group and $4.90 \pm 8.99$ in the NAS group. Immediately after

Table 2 Comparison of clinical outcomes between the two groups

\begin{tabular}{|l|l|l|l|}
\hline Variables & AS $(\mathbf{n}=\mathbf{3 5})$ & NAS $(\mathbf{n}=82)$ & $P$-value \\
\hline JOA & & & \\
Preop & $10.17 \pm 2.51$ & $10.28 \pm 2.81$ & 0.844 \\
Postop & $13.74 \pm 1.73^{\mathrm{a}}$ & $13.86 \pm 1.92^{\mathrm{a}}$ & 0.745 \\
Final FU & $13.62 \pm 1.98^{\mathrm{a}}$ & $13.50 \pm 2.11^{\mathrm{a}}$ & 0.760 \\
JOA recovery rate (\%) & & & \\
Postop & $53.85 \pm 14.73$ & $56.70 \pm 19.95$ & 0.448 \\
Final FU & $50.37 \pm 22.87$ & $51.59 \pm 21.49$ & 0.783 \\
VAS neck & & & \\
Preop & $4.25 \pm 1.88$ & $4.10 \pm 1.91$ & 0.703 \\
Postop & $3.37 \pm 1.13^{\mathrm{a}}$ & $2.78 \pm 1.16^{\mathrm{a}}$ & 0.013 \\
Final FU & $5.14 \pm 0.9 I^{\mathrm{a}}$ & $3.02 \pm 1.39^{\mathrm{a}}$ & $<0.001$ \\
\hline
\end{tabular}

Notes: ${ }^{P}<0.05$ compared with preoperative value.

Abbreviations: AS, axial symptoms; FU, follow-up; JOA, Japanese Orthopaedic Association; NAS, no axial symptoms; Postop, postoperative; Preop, preoperative; VAS, Visual Analog Scale. 
surgery, the measurements were $7.31 \pm 6.66$ and $7.58 \pm 6.86$, respectively. At the last FU, segmental angles were $6.14 \pm 6.27$ and $6.53 \pm 6.51$ in the two groups. Significant differences were found between the two groups at preoperation (Table 3).

The IH before and after surgery and at the final FU are given in Table 4. The mean IHs of the two groups were significantly increased after surgery $(P<0.05)$, but later decreased at the final FU $(P<0.05)$, although still greater than the baseline value $(P<0.05)$. There were no significant differences $(P>0.05)$ between the AS and NAS groups before and after the operation. Similarly, for IH variation, no significant difference $(P>0.05)$ was found between the two groups.

\section{Risk factors of AS}

To identify correlative risk factors that influence AS following $\mathrm{ACDF}$, we performed a logistic regression analysis. Multivariate logistic regression analysis revealed preoperative segmental kyphosis (Figure 1) and preoperative MCs (Figure 2) adjacent to the operated vertebral body to be significant risk factors for developing postoperative $\mathrm{AS}$ (segmental kyphosis: $\mathrm{OR}=2.912$ [95\% CI $=1.080-7.855], P=0.035$; MCs: OR $=3.268[95 \%$ $\mathrm{CI}=1.255-8.511], P=0.015)$, whereas age, gender, smoking status, BMI, number of surgical levels, and IH change did not significantly affect the incidence of AS (Table 5).

Table 3 Comparison of radiological outcomes between the two groups

\begin{tabular}{|l|l|l|l|}
\hline Variables & AS (n=35) & NAS $(\mathbf{n = 8 2})$ & P-value \\
\hline $\begin{array}{l}\text { Cervical alignment } \\
\text { Preop }\end{array}$ & $5.62 \pm 8.17$ & $7.71 \pm 7.89$ & 0.197 \\
Postop & $12.88 \pm 8.24^{\mathrm{a}}$ & $13.30 \pm 7.28^{\mathrm{a}}$ & 0.785 \\
Final FU & $11.65 \pm 6.84^{\mathrm{a}}$ & $12.42 \pm 5.85^{\mathrm{a}}$ & 0.538 \\
Segmental angle & & & \\
Preop & $0.94 \pm 8.96$ & $4.90 \pm 8.99$ & 0.031 \\
Postop & $7.31 \pm 6.66^{\mathrm{a}}$ & $7.58 \pm 6.86^{\mathrm{a}}$ & 0.844 \\
Final FU & $6.14 \pm 6.27^{\mathrm{a}}$ & $6.53 \pm 6.5 \mathrm{I}^{\mathrm{a}}$ & 0.763 \\
\hline
\end{tabular}

Notes: ${ }^{a} P<0.05$ compared with preoperative value.

Abbreviations: AS, axial symptoms; FU, follow-up; NAS, no axial symptoms; Postop, postoperative; Preop, preoperative.

Table 4 Comparison of IH between the two groups

\begin{tabular}{|l|l|l|l|}
\hline Variables & AS $(\mathbf{n}=\mathbf{3 5})$ & NAS $(\mathbf{n = 8 2})$ & $P$-value \\
\hline $\mathrm{IH}(\mathrm{mm})$ & & & \\
$\quad$ Preop & $34.67 \pm 1.40$ & $34.36 \pm 1.35$ & 0.273 \\
Postop & $38.12 \pm 1.7 \mathrm{I}^{\mathrm{a}}$ & $37.95 \pm 1.46^{\mathrm{a}}$ & 0.584 \\
$\quad$ Final FU & $37.3 \mathrm{I} \pm 1.58^{\mathrm{a}}$ & $37.2 \mathrm{I} \pm 1.55^{\mathrm{a}}$ & 0.765 \\
$\mathrm{IH}$ change $(\mathrm{mm})^{\mathrm{b}}$ & $3.45 \pm \mathrm{I} .19$ & $3.58 \pm 0.97$ & 0.527 \\
\hline
\end{tabular}

Notes: ${ }^{a} P<0.05$ compared with preoperative value. ${ }^{b} D$ ifference between $\mathrm{IH}$ before and after the surgery.

Abbreviations: AS, axial symptoms; FU, follow-up; IH, intervertebral height; NAS, no axial symptoms; Postop, postoperative; Preop, preoperative.

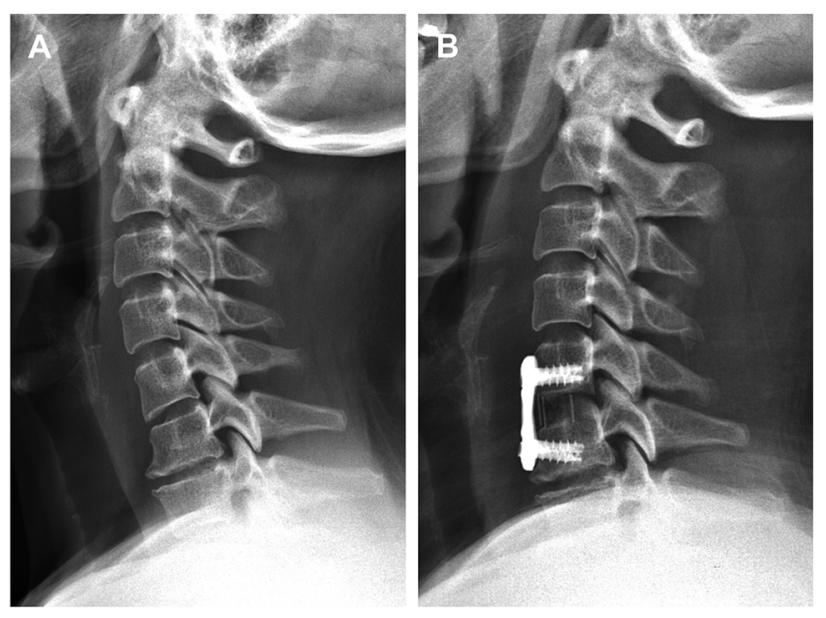

Figure I A 62-year-old male patient with segmental kyphosis on C5-C6 before surgery (A), the segmental kyphosis was corrected after surgery (B), but AS were detected at the 3-month FU.

Abbreviations: AS, axial symptoms; FU, follow-up.

\section{Discussion}

AS are common after cervical spine surgery and can cause significant inconvenience to patients by affecting their working and social lives and reducing the curative effect of treatment. ${ }^{10}$ Various mechanisms have been suggested to explain the occurrence of AS following cervical posterior decompression surgery, including damage to the posterior muscle-ligament complex during surgery, change in the physiological curvature of the cervical vertebrae, and intervertebral instability. ${ }^{7,23-25}$ Nevertheless, few studies have investigated the cause of AS after ACDF. Hence, we conducted this study to explore the risk factors affecting AS following ACDF.

According to relevant literature, the incidence of AS in patients following ACDF was 38.3\%. ${ }^{9}$ In our study, the occurrence rate of AS was $29.91 \%$. Meanwhile, we observed that patients who underwent ACDF achieved significant improvement after a minimum 1-year FU. Compared with the NAS group, the AS group showed similar clinical results with respect to the JOA score and JOA recovery rate, meaning the occurrence of AS was not obviously correlated with the recovery of neural function after surgery, which is consistent with previous literature. ${ }^{10,20}$

Few studies have shown an improvement of cervical alignment after anterior cervical decompression surgery. ${ }^{26,27}$ In our study, both global and segmental curvatures of the two groups improved significantly after surgery. An earlier study indicated that preoperative $\mathrm{C} 2-\mathrm{C} 7$ kyphosis and preoperative local kyphosis are probable risk factors for poor surgical outcomes. ${ }^{28}$ In our study, we found that the preoperative segmental angle correlates with AS occurrence after ACDF. 

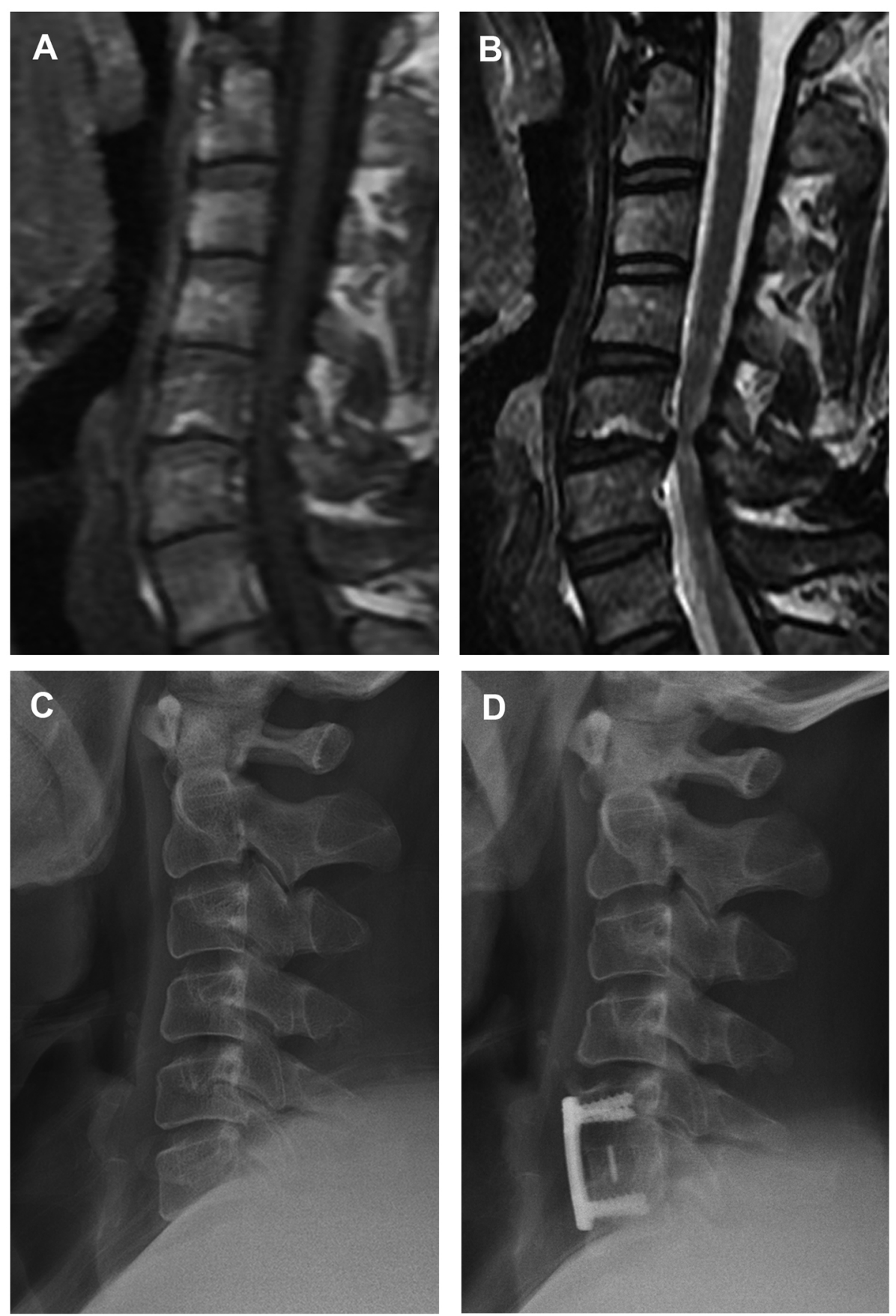

Figure 2 A 55-year-old male patient with AS.

Notes: Preoperative MRI showed MC2 in the $C 5$ endplate (A and B). From preoperative radiograph (C), the $C 2-C 7$ Cobb angle is $9.4^{\circ}$, the segmental angle is $7.4^{\circ}$, and the $\mathrm{IH}$ is $37.3 \mathrm{~mm}$. From the postoperative radiograph (D), the C2-C7 Cobb angle is $10.3^{\circ}$, the segmental angle is $10.7^{\circ}$, and the $\mathrm{IH}$ is $39.5 \mathrm{~mm}$.

Abbreviations: AS, axial symptoms; IH, intervertebral height; MC2, type II Modic changes; MRI, magnetic resonance imaging.

The risk of AS was 2.9-fold greater in the segmental kyphotic group than in the segmental lordotic group. In another study, researchers reported that the occurrence rate of segmental kyphosis was higher in patients with AS than in those without AS. One possible reason is that kyphosis causes the imbalance of neck muscles and zygapophyseal joints, eventually leading to the formation of AS. ${ }^{9}$
In addition, we found a significant correlation between preoperative MCs and occurrence of AS. The pathogenetic mechanisms causing MCs are not very clear. Microfractures and endplate fissures have been identified as a major source of MCs through biomechanical mechanism. The abnormal load and stress will affect vertebral endplates and the microenvironment of adjacent vertebral bone marrow, resulting in 
Table 5 Logistic regression analysis for the risk factors of AS

\begin{tabular}{|c|c|c|c|c|c|c|}
\hline \multirow[t]{2}{*}{ Variables } & \multirow{2}{*}{$\begin{array}{l}\text { AS } \\
(n=35)\end{array}$} & \multirow{2}{*}{$\begin{array}{l}\text { NAS } \\
(n=82)\end{array}$} & \multicolumn{2}{|l|}{ Univariate } & \multicolumn{2}{|l|}{ Multivariate $^{a}$} \\
\hline & & & OR $(95 \% \mathrm{Cl})$ & $P$-value & OR $(95 \% \mathrm{CI})$ & $P$-value \\
\hline \multicolumn{7}{|l|}{ Age (years) } \\
\hline$\geq 60$ & 15 & 26 & $1.615(0.715-3.650)$ & 0.249 & & \\
\hline$<60$ & 20 & 56 & & & & \\
\hline \multicolumn{7}{|l|}{ Gender } \\
\hline Male & 16 & 45 & $0.692(0.3 \mid 3-1.533)$ & 0.365 & & \\
\hline Female & 19 & 37 & & & & \\
\hline \multicolumn{7}{|l|}{ Smoking } \\
\hline Smoker & 9 & 17 & $1.324(0.524-3.345)$ & 0.553 & & \\
\hline Nonsmoker & 26 & 65 & & & & \\
\hline \multicolumn{7}{|l|}{$\mathrm{BMI}\left(\mathrm{kg} / \mathrm{m}^{2}\right)$} \\
\hline$\geq 24$ & 22 & 46 & $1.324(0.588-2.985)$ & 0.498 & & \\
\hline$<24$ & 13 & 36 & & & & \\
\hline \multicolumn{7}{|l|}{ Level } \\
\hline $\mathrm{C} 3 / 4$ & 3 & 9 & I & 0.662 & & \\
\hline $\mathrm{C} 4 / 5$ & 6 & 20 & $0.900(0.183-4.429)$ & 0.897 & & \\
\hline $\mathrm{C} 5 / 6$ & 15 & 35 & $1.286(0.305-5.426)$ & 0.732 & & \\
\hline $\mathrm{C} 6 / 7$ & 11 & 18 & $1.833(0.406-8.271)$ & 0.430 & & \\
\hline \multicolumn{7}{|c|}{ Preoperative cervical alignment } \\
\hline Kyphosis & 7 & 9 & $2.403(0.84 I-6.866)$ & 0.102 & $1.236(0.379-4.035)$ & 0.726 \\
\hline Lordosis & 28 & 73 & & & & \\
\hline \multicolumn{7}{|c|}{ Preoperative segmental angle $\left({ }^{\circ}\right)$} \\
\hline Kyphosis & 15 & 19 & $2.478(1.070-5.780)$ & 0.034 & $2.912(1.080-7.855)$ & 0.035 \\
\hline Lordosis & 20 & 63 & & & & \\
\hline \multicolumn{7}{|c|}{ Preoperative MC } \\
\hline Yes & 13 & 15 & $2.639(1.089-6.396)$ & 0.032 & $3.268(1.255-8.5 \mathrm{II})$ & 0.015 \\
\hline No & 22 & 67 & & & & \\
\hline \multicolumn{7}{|c|}{ Distraction of $\mathrm{IH}(\mathrm{mm})$} \\
\hline$\leq 2$ & 3 & 9 & 1 & 0.837 & & \\
\hline $2-5$ & 28 & 66 & $1.273(0.320-5.056)$ & 0.732 & & \\
\hline$\geq 5$ & 4 & 7 & $1.714(0.285-10.303)$ & 0.556 & & \\
\hline
\end{tabular}

Notes: ${ }^{\text {TT }}$ The multivariate model includes variables with $P<0.20$ by univariate analysis.

Abbreviations: AS, axial symptoms; BMI, body mass index; IH, intervertebral height; MC, Modic changes; NAS, no axial symptoms.

histological changes, which exhibit signal intensity change on MRI, namely MCs. ${ }^{11}$ Besides, the higher levels of proinflammatory mediators such as interleukin-6, interleukin-8, and prostaglandin E2 from the disc could cause chronic inflammation of the adjacent bone marrow. ${ }^{29,30}$ MCs have been proven to be associated with neck pain in the cervical spine. ${ }^{19}$ In the current study, we found that, in patients who underwent ACDF, the risk of AS was 3.2-fold greater in the MCs group than in the non-MCs group.

Our study has some limitations. This was a single-center retrospective study, which may induce potential biases. In addition, the sample size in this study was not large enough. Lack of long-term FU was another limitation in our study. Further multicenter prospective studies with long-term FU are needed to evaluate the association between clinical outcomes and AS and relevant risk factors.

\section{Conclusion}

AS are a common phenomenon following ACDF but do not affect recovery of neural function. Preoperative segmental kyphosis and MCs are correlative risk factors for occurrence of AS.

\section{Acknowledgments}

The authors thank all the research assistants and patients for their time and efforts in this study. This research was supported by the National Natural Science Foundation of China (Grant No 81471403).

\section{Author contributions}

All authors contributed toward data analysis, drafting, critical revision of the paper, gave approval for the final version to be published, and agreed to be accountable for all aspects of the work. 


\section{Disclosure}

The authors report no conflicts of interest in this work.

\section{References}

1. Tracy JA, Bartleson JD. Cervical spondylotic myelopathy. Neurologist. 2010;16(3):176-187.

2. Kalsi-Ryan S, Karadimas SK, Fehlings MG. Cervical spondylotic myelopathy: the clinical phenomenon and the current pathobiology of an increasingly prevalent and devastating disorder. Neuroscientist. 2013;19(4):409-421.

3. Smith GW, Robinson RA. The treatment of certain cervical-spine disorders by anterior removal of the intervertebral disc and interbody fusion. J Bone Joint Surg Am. 1958;40A(3):607-624.

4. Cloward RB. The anterior approach for removal of ruptured cervical disks. J Neurosurg. 1958;15(6):602-617.

5. Bohlman HH, Emery SE, Goodfellow DB, Jones PK. Robinson anterior cervical discectomy and arthrodesis for cervical radiculopathy. Longterm follow-up of one hundred and twenty-two patients. $J$ Bone Joint Surg Am. 1993;75(9):1298-1307.

6. Emery SE, Bohlman HH, Bolesta MJ, Jones PK. Anterior cervical decompression and arthrodesis for the treatment of cervical spondylotic myelopathy. Two to seventeen-year follow-up. J Bone Joint Surg Am. 1998;80(7):941-951.

7. Sun Y, Zhang F, Wang S, et al. Open door expansive laminoplasty and postoperative axial symptoms: a comparative study between two different procedures. Evid Based Spine Care J. 2010;1(3):27-34.

8. Hosono N, Yonenobu K, Ono K. Neck and shoulder pain after laminoplasty. A noticeable complication. Spine. 1996;21(17):1969-1973.

9. Kawakami M, Tamaki T, Yoshida M, Hayashi N, Ando M, Yamada H. Axial symptoms and cervical alignments after cervical anterior spinal fusion for patients with cervical myelopathy. $J$ Spinal Disord. 1999;12(1):50-56.

10. Iizuka $H$, Nakajima $T$, Iizuka $Y$, et al. Cervical malalignment after laminoplasty: relationship to deep extensor musculature of the cervical spine and neurological outcome. J Neurosurg Spine. 2007;7(6):610-614

11. Modic MT, Steinberg PM, Ross JS, Masaryk TJ, Carter JR. Degenerative disk disease: assessment of changes in vertebral body marrow with MR imaging. Radiology. 1988;166(1 Pt 1):193-199.

12. Modic MT, Masaryk TJ, Ross JS, Carter JR. Imaging of degenerative disk disease. Radiology. 1988;168(1):177-186.

13. Ross JS, Modic MT. Current assessment of spinal degenerative disease with magnetic resonance imaging. Clin Orthop Relat Res. 1992;279(279):68-81.

14. Chung $\mathrm{CB}$, vande Berg BC, Tavernier T, et al. End plate marrow changes in the asymptomatic lumbosacral spine: frequency, distribution and correlation with age and degenerative changes. Skeletal Radiol. 2004;33(7):399-404.

15. Albert HB, Briggs AM, Kent P, Byrhagen A, Hansen C, Kjaergaard $\mathrm{K}$. The prevalence of MRI-defined spinal pathoanatomies and their association with Modic changes in individuals seeking care for low back pain. Eur Spine J. 2011;20(8):1355-1362.
16. Kjaer P, Korsholm L, Bendix T, Sorensen JS, Leboeuf-Yde C. Modic changes and their associations with clinical findings. Eur Spine J. 2006;15(9):1312-1319.

17. Jensen TS, Karppinen J, Sorensen JS, Niinimäki J, Leboeuf-Yde C. Vertebral endplate signal changes (Modic change): a systematic literature review of prevalence and association with non-specific low back pain. Eur Spine J. 2008;17(11):1407-1422.

18. Kuisma M, Karppinen J, Niinimäki J, et al. Modic changes in endplates of lumbar vertebral bodies: prevalence and association with low back and sciatic pain among middle-aged male workers. Spine. 2007;32(10):1116-1122.

19. Sheng-Yun L, Letu S, Jian C, et al. Comparison of Modic changes in the lumbar and cervical spine, in 3167 patients with and without spinal pain. PLoS One. 2014;9(12):e114993.

20. Li J, Lei T, Shen Y. The impact of Modic-2 changes on the clinical outcomes of single-level anterior cervical discectomy and fusion. Eur Spine J. 2015;24(12):2936-2940.

21. Scott PJ, Huskisson EC. Measurement of functional capacity with visual analogue scales. Rheumatol Rehabil. 1977;16(4):257-259.

22. Ohara A, Miyamoto K, Naganawa T, Matsumoto K, Shimizu K. Reliabilities of and correlations among five standard methods of assessing the sagittal alignment of the cervical spine. Spine. 2006;31(22): 2585-2591.

23. Iizuka H, Shimizu T, Tateno K, et al. Extensor musculature of the cervical spine after laminoplasty: morphologic evaluation by coronal view of the magnetic resonance image. Spine. 2001;26(20):2220-2226.

24. Sasai K, Saito T, Akagi S, Kato I, Ogawa R. Cervical curvature after laminoplasty for spondylotic myelopathy-involvement of yellow ligament, semispinalis cervicis muscle, and nuchal ligament. $J$ Spinal Disord. 2000;13(1):26-30.

25. Takeuchi K, Yokoyama T, Aburakawa S, et al. Axial symptoms after cervical laminoplasty with C3 laminectomy compared with conventional C3-C7 laminoplasty: a modified laminoplasty preserving the semispinalis cervicis inserted into axis. Spine. 2005;30(22): 2544-2549.

26. Cabraja M, Abbushi A, Koeppen D, Kroppenstedt S, Woiciechowsky C. Comparison between anterior and posterior decompression with instrumentation for cervical spondylotic myelopathy: sagittal alignment and clinical outcome. Neurosurg Focus. 2010;28(3):E15.

27. Edwards CC, Heller JG, Murakami H. Corpectomy versus laminoplasty for multilevel cervical myelopathy: an independent matched-cohort analysis. Spine. 2002;27(11):1168-1175.

28. Suda K, Abumi K, Ito M, Shono Y, Kaneda K, Fujiya M. Local kyphosis reduces surgical outcomes of expansive open-door laminoplasty for cervical spondylotic myelopathy. Spine. 2003;28(12):1258-1262.

29. Burke JG, Watson RW, McCormack D, Dowling FE, Walsh MG, Fitzpatrick JM. Intervertebral discs which cause low back pain secrete high levels of proinflammatory mediators. J Bone Joint Surg Br. 2002;84(2):196-201.

30. Wedderkopp N, Thomsen K, Manniche C, Kolmos HJ, Secher Jensen T, Leboeuf Yde C. No evidence for presence of bacteria in Modic type I changes. Acta Radiol. 2009;50(1):65-70.
Journal of Pain Research

\section{Publish your work in this journal}

The Journal of Pain Research is an international, peer reviewed, open access, online journal that welcomes laboratory and clinical findings in the fields of pain research and the prevention and management of pain. Original research, reviews, symposium reports, hypothesis formation and commentaries are all considered for publication.
The manuscript management system is completely online and includes a very quick and fair peer-review system, which is all easy to use. Visit http://www.dovepress.com/testimonials.php to read real quotes from published authors. 